\title{
Analysis of Contribution of Employees`Team Building Programs on Performance of Mobile Telephone Network Operators in Kenya
}

\author{
Grace K. Karemu $^{1 \star} \quad$ Prof. Musa Nyakora ${ }^{2} \quad$ Dr. Erastus Thoronjo ${ }^{3} \quad$ Dr. Evans Nyamboga ${ }^{3}$ \\ 1. Scholar, School of Business and Economics, Mount Kenya University, P. O. Box 342-01000, Thika, Kenya \\ 2. Dean of students, School of Post-graduate studies, Adventist University of Africa, Private bag, Mbagathi, \\ Kenya \\ 3. Doctor, School of Business and Economics, Mount Kenya University, P. O. Box 342-01000, Thika, Kenya
}

\begin{abstract}
Team building is the process of causing a group of people to work together effectively as a team, especially by means of activities and events designed to increase motivation and promote cooperation. Effective teamwork allows teams to produce outcomes greater than the sum of individual members. The objective of the study was to determine contribution of employees` team building programs on performance of Mobile Telephone Network Operators (MTNOs) in Kenya. Variables used to analyze contribution of employees` team building programs on performance of Mobile Telephone Network Operators (MTNOs) in Kenya were team building workshops, team building seminars and team bonding meetings. Performance of Mobile Telephone Operators was analyzed in terms of profit margins and market share. Social identity theory was used to explain the contribution of employees` team building programs on performance. Study population was 6,167 which included all the employees in the Mobile Telephone Network Operators in Kenya and a total sample size of 361 employees was obtained although only 258 questionnaires were filled and returned. Proportionate stratification formula was used to allocate sample sizes to each department of the Mobile Telephone Operators. Data analysis was done using descriptive statistics and inferential statistics. The hypothesis was tested at $95 \%$ confidence interval and $0.05 \alpha$ level of significance. Study $\mathrm{H}_{0}$ stated that: employees` team building programs have no significant relationship with performance of MTNOs in Kenya. Goodness of fit model demonstrated that team building programs had a positive influence on performance of MTNOs accounting for $38.1 \%$ of the performance $(\mathrm{R}$ squared $=.381)$. The study concluded that there was a statistically significant influence of team building programs on performance therefore rejecting the null hypothesis at $\beta=.617, \mathrm{P}=.000$.
\end{abstract}

Keywords: Team Building Programs, Performance, MTNOs in Kenya

DOI: $10.7176 / \mathrm{EJBM} / 13-11-07$

Publication date:June $30^{\text {th }} 2021$

\section{Introduction}

Team building is the action or process of causing a group of people to work together effectively as a team, especially by means of activities and events designed to increase motivation and promote cooperation (Oxford dictionary). According to a survey conducted by Deloitte across 130 countries and over 7,000 participants, the number one global workforce trend is team building to achieve effective teamwork for improved performance (Kaplan et al., 2016). This is because effective teamwork allows teams to produce outcomes greater than the sum of individual members. Team building is an intervention designed to foster improvement within a team, by providing individuals closely involved with the task strategies, information and trust needed to solve their own problems.

Company`s management can use team building programs to enhance the success of teams through inspiration, motivation, and leadership by encouraging teams to see themselves mutually accountable and responsible for their outcomes (Gino, 2015): This is achieved when team members focus on team goals relying on each another's abilities to improve team performance to own and accomplish activities efficiently and effectively. Team-building interventions help employees improve their teamwork, problem-solving, communication, and conflictmanagement skills (Guchait et al., 2016). Team building activities also promote consensus among misaligned teammates, strengthens relationships and collaboration increasing the level of commitment and responsibility: This unites employees behind a common goal and creates feelings of ownership toward their team goals and their company, hence increasing performance of the company (Udu \& Aturu-Aghedo, 2016. The synergy coming from teams while concentrating efforts on activities makes the activities easier and faster to complete (Armstrong, 2012).

\subsection{Statement of the Problem}

According to Communications Authority of Kenya (CAK) sectorial reports, MTNOs in Kenya are faced with many performance challenges which include low to negative financial returns, drop in mobile money market share, decrease in mobile Short Messages (SMSs), reduced mobile voice traffic and drop in subscribers' market share. 
Airtel Kenya MTNO reported that it was bankrupt and could not meet its financial obligations and that the company was crumbling under over Sh55 billion short term debts whereas the current assets were about Kshs 10 billion reflecting a bad performance: The situation led to a Kshs 8 billion loss in 2016 and the MTNO had losses worth Sh59.3 billion by December, 2017 (Airtel annual report, 2017). Telkom Kenya in the last 10 years has faced problems which made profitability for the MTNO a mirage, and as a result the company has always reported low performance. The MTNO then decided to compete by lowering calling prices but suffered consequences due to lowering mobile call charges too low to lure subscribers, since the strategy plunged the company into further debts and losses (Telkom Kenya annual reports of 2015, 2016 \& 2017). Safaricom Ltd also has had its share of performance challenges over the years reporting a drop in its mobile money market share in 2014, a decline in subscribers market share in 2015, a loss in SMSs market share in 2016 and a decrease in local voice traffic in 2017 (Communications Authority of Kenya , 2015, 2016, 2017).

\subsection{Objective of the Study}

The objective of the study was to determine contribution of employees team building programs on performance of MTNOs in Kenya.

\subsection{Research Hypothesis}

The study tested the null hypothesis which was stated as, $\mathrm{H}_{0}$ : Employees' team building programs have no significant relationship with performance of MTNOs in Kenya.

\section{Theoretical Review}

\subsection{The Social Identity Theory}

This theory was suggested by Tajfel, (1978) and its application to the organizational context was proposed by Ashforth (1989). Organizational identification arises from social identity emanating from team building programs; which leads cohesive teams from which employees find emotional attachment to the organization and their jobs resulting to increased commitment, increased responsibility and sense of ownership; which interprets to increased organizational performance (Ciasullo et al., 2017). Banerjee, (2014) posited that team building activities gives rise to employee teams with high executive power, able to perform organizational functions better than other teams and at the same time gives team members social identity both at group level and at organizational level. Social identity theory argues that team building programs motivate employees such that they assist one another in accomplishing team goals to ensure all team members remain accountable and responsible when participating in team roles (Ciasullo et al., 2017).

Team building programs brings about teamwork and team identity which are tools for increasing job satisfaction for higher organizational performance. Such programs bring team spirit, increasing employee productivity and promoting corporate culture especially if the teamwork culture is institutionalized prior to formation teams Trepte \& Loy (2017). Banerjee (2014) underscores that team building activities brings about shared identity which is an important aspect of building a team, transforming a group of employees into a cohesive, focused work team; Consensus building, which help to create trust and connections among the employees is another important aspect of team building that can help develop organization's identity and provide ways of nurturing organization bonding to give employees singleness of purpose in accomplishing organizational goals for advanced performance. Social identity theory argues that as employees socialize during team-building exercises they can develop team spirit; cooperation between them and a strong bond that can help them work amicably for improved performance (Tajfel, 1978). The theory posits that as the senior employees socialize with their junior counterparts during team building activities, there is more cooperation as they get to acknowledge individual strengths and weaknesses, bringing better understanding of one another for better working relationships and for better productivity (Mael \& Ashforth, 2001).

\subsection{Literature Review: Employee Team Building Programs on Performance}

Several researchers have done research on the effect of team building programs (or activities) on company`s and employees ` performance and have published findings: Al Salman \& Hassan, (2017) researched on how employee teamwork of a company in Malaysia affected employee performance. Using questionnaires, the researcher got primary data from a sample of 107 employees of the company through simple sampling. Independent variables which were used to measure teamwork were communication, cohesiveness, accountability, interpersonal skills, leadership ability and the level of trust. Data analysis obtained standardized and unstandardized coefficients: study results showed that all the factors used to measure teamwork had a significant relationship with employee performance. Al Salman \& Hassan, (2017) found that Beta coefficient for effective communication was statistically significant at Beta $=0.117$ and $\mathrm{P}=0.012$ meaning that communication within teams impacted employee performance. Trust showed a Beta $=0.962$ and $\mathrm{P}=0.000$, meaning that the extent to which employees trusted management had notable effect on employee performance. Another factor which defined teamwork, was 
leadership ability which had negatively impacted on employee performance (Beta $-0.231, \mathrm{P}=0.001$ ):

Hultin, et al., (2017, did a study to find out whether team building supports creation of high-performing teams at Lund University in Sweden. The researchers purposed to establish how team building programs correlated with team performance. The study took place at Lund University, Sweden and primary data was gathered from 215 respondents. Research outcome indicated a correlation of $\mathrm{r}=0.521$ meaning an effective association existed between team building and team performance. Two-tailed significance was at $\mathrm{P}=0.000$, showing a high trustworthiness of results, meaning a great constructive association existed between team building programs and team performance. The study concluded that team building programs helps build high quality teams which are able to influence firm's performance positively.

Sanyal \& Hisam, (2018) demonstrated how employees` teamwork correlates with their performance. The researchers` hypothesis was that teamwork does not significantly affect performance in Dhofar University. Results showed coefficient (r) was 0.819. Sanyal \& Hisam, (2018) demonstrated that teamwork and performance were highly and positively correlated, hence the rejection of the null hypothesis at $\mathrm{P}=0.01$ levels of significance since the research found teamwork explained $81.9 \%$ of performance at the university. It was further concluded that employees` team building programs were important for improving employees` performance. Manzoor, et al., (2011) also studied teamwork to establish how it affected performance of employees in Peshawar Province of Pakistan. Study population consisted of 242 employees of higher education department. After analysis of data on teamwork F-value of 120.140 was obtained. Regression coefficient was $\mathrm{R}=.843$ or $84.3 \%$ meaning that a noteworthy positive correlation existed between teamwork and performance. Doan, (2015) studied how teamwork enhances team spirit by use of various activities. The objective of research was to assess effectiveness of teamwork programs in providing Human Orientation for Sustainable Excellent services (HOSE) in Nha Trang, Vietnam. Six teams of 33-35 members with team leaders drawn from middle management of HOSE were studied consisting of 201 participants. All teams used in the study were effective, meaning they were made of suitable participants with the right ability and experiences necessary for effective problem-solving, and were ready to deal with team challenges, supporting each other, and focusing to achieve expected results while exhibiting appropriate personal styles.

Doan, (2015) found that in the context of Vietnamese public sector employees' teambuilding programs enhanced culture of teamwork through teambuilding activities by enabling participants to develop the right orientation, abilities and conduct. Developing strong team bonds through team building activities ends up strengthening sense of belonging, responsibility and accountability hence promoting institutional ownership culture. Doan, (2015) recommended employees` team building programs in the current business world since teamwork rather than individuals` work brings about greater performance even in the midst of fierce competitors. Doan, (2015) also suggested that management of companies should apply the recommendations in the study and nurture cohesive employees` teamwork toward building a corporate culture of ownership.

\subsection{The conceptual Framework}

Team building programs formed the independent variable while organizations` performance was the dependent variable as presented in figure 1

\section{Independent Variable}

$$
\begin{array}{ll}
\text { Employee team building programs: } \\
\circ & \text { Team building workshops } \\
\circ & \text { Team building seminars } \\
\circ & \text { Team bonding meetings }
\end{array}
$$

Dependent Variable

\section{Performance:}

- $\quad$ Profit Margins

- Market share

$$
\text { O Team bonding meetings }
$$

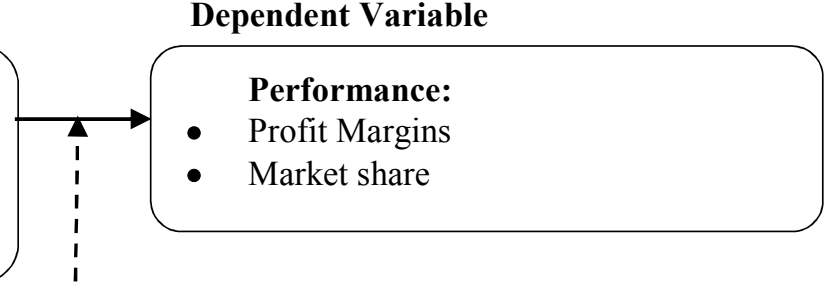

\begin{tabular}{|ll|}
\hline - Intervening Variables \\
- & Government Policies \\
&
\end{tabular}

Figure 1: Conceptual Framework

Source: Researcher, 2019

\section{Research Methodology and Design}

Quantitative methodology was used where primary quantitative data was collected and analyzed on opinions of employees concerning team building programs (which was studied in terms of team building workshops, team building seminars and team bonding meetings) with regard to their influence on company`s performance. The methodology extended to counting the opinions and constructing statistical models to explain what was observed, 
according to Edson et al., (2016). Cross-sectional survey design helped this study in establishing relationships between study variables namely team building programs and organization`s performance. According to Wilson (2010), a cross-sectional research design helps in checking for significant associations between variables and in making generalizations concerning the target population.

\subsection{Target Population}

The researcher targeted all the employees of MTNOs in Kenya. According to the company`s end of year report, (2018) employee count at Safaricom MTNO were 4,245 as at December 2018 as indicated by the MTNOs company report. The second part of the population included all employees of Airtel in Kenya, who were 1,136 according to Airtel company report of December, 2018 and the third portion of the population comprised of 786 permanent employees at Telkom Kenya MTNO according to company`s annual report of 2018. The total population under study was therefore 6,167 employees from the three MTNOs as shown in table 1 below.

Table 1: Target Population

\begin{tabular}{lcccc}
\hline Department & Safaricom & Airtel & Telkom Kenya & Total population \\
\hline Finance & 94 & 33 & 23 & 150 \\
Mobile money & 262 & 76 & 53 & 391 \\
HRM & 96 & 21 & 17 & 134 \\
Procurement & 57 & 18 & 15 & 90 \\
Marketing & 316 & 134 & 94 & 544 \\
Customer care & 1282 & 423 & 287 & 1992 \\
Innovations & 93 & 46 & 36 & 175 \\
Network Engineering & 167 & 58 & 41 & 266 \\
Business unit & 64 & 27 & 18 & 109 \\
Strategy MGT & 253 & 32 & 23 & 308 \\
Sales MGT & 1052 & 141 & 96 & 1289 \\
Operations & 437 & 94 & 62 & 593 \\
Distribution & $\mathbf{7 2}$ & 33 & $\mathbf{7 8 6}$ & 126 \\
\hline Total & $\mathbf{4 , 2 4 5}$ & $\mathbf{1 , 1 3 6}$ & $\mathbf{6 , 1 6 7}$
\end{tabular}

Source: Safaricom Kenya, Airtel Kenya and Telkom Kenya records, (2019)

\subsection{Sampling Procedure, Techniques and sample size}

Since the total population of this study was 6,167 employees, the researcher obtained a sample size from Krejcie \& Morgan, (1970) sample size table which gave 361 employees from the three MTNOs. The proportionate stratification formula as was developed by Sukhatme et al, (1984) was used to ensure that sample sizes assigned to these departments were proportionate to the number of employees in the department as presented in table 2 .

$\mathrm{n}_{\mathrm{h}}=\frac{\mathrm{N}_{\mathrm{h}}}{\mathrm{N}} \times \mathrm{n}$

Where :

$\begin{array}{lll}\mathrm{n}_{\mathrm{h}} & = & \text { sample size for department, } \mathrm{h} \\ \mathrm{N}_{\mathrm{h}} & = & \text { the population size for department, } \mathrm{h} \\ \mathrm{N} & = & \text { total population size } \\ \mathrm{n} & = & \text { total sample size }\end{array}$


Table 2 Sample Size

\begin{tabular}{|c|c|c|c|c|c|c|c|c|}
\hline $\begin{array}{l}\text { Stratum or } \\
\text { Department }\end{array}$ & $\begin{array}{c}\text { S/com } \\
\text { T/P }\end{array}$ & S/S (n) & $\begin{array}{c}\text { Airtel } \\
\mathbf{T} / \mathbf{P}\end{array}$ & S/S (n) & $\begin{array}{c}\text { T/kom } \\
\text { T/P }\end{array}$ & $\begin{array}{l}\mathrm{S} / \mathrm{S} \\
\text { (n) }\end{array}$ & $\begin{array}{l}\text { MTNOs } \\
\text { T/P }\end{array}$ & $\begin{array}{l}\text { Total } \\
\text { S/S (n) }\end{array}$ \\
\hline Finance & 94 & 6 & 33 & 2 & 23 & 1 & 150 & 9 \\
\hline Mobile money & 262 & 15 & 76 & 4 & 53 & 3 & 391 & 22 \\
\hline HRM & 96 & 6 & 21 & 1 & 17 & 1 & 134 & 8 \\
\hline Procurement & 57 & 3 & 18 & 1 & 15 & 1 & 90 & 5 \\
\hline Marketing & 316 & 18 & 134 & 8 & 94 & 6 & 544 & 32 \\
\hline Customer care & 1282 & 75 & 423 & 25 & 287 & 17 & 1,992 & 117 \\
\hline Innovations & 93 & 5 & 46 & 3 & 36 & 2 & 175 & 10 \\
\hline Engineering & 167 & 10 & 58 & 3 & 41 & 2 & 266 & 15 \\
\hline Business unit & 64 & 4 & 27 & 1 & 18 & 1 & 109 & 6 \\
\hline Strategy MGT & 253 & 15 & 32 & 2 & 23 & 1 & 308 & 18 \\
\hline Sales MGT & 1052 & 62 & 141 & 8 & 96 & 6 & 1,289 & 76 \\
\hline Operations & 437 & 25 & 94 & 6 & 62 & 5 & 593 & 36 \\
\hline Distribution & 72 & 4 & 33 & 2 & 21 & 1 & 126 & 7 \\
\hline Total & 4,245 & 248 & 1,136 & 66 & 786 & 47 & 6,167 & 361 \\
\hline
\end{tabular}

Source: Researcher, 2019

Key: T/P-Total Population, S/S-Sample Size, S/com-Safaricom, T/com- Telkom

\subsection{Data Processing, Analysis Techniques and Procedures}

The approach to research which guided data processing and analysis in this study was the positivist approach where quantitative facts were analyzed for hypothesis testing utilizing quantitative tests according to (Sekaran \& Bougie, 2016). Positivists' set down a strong prominence on ascribing quantitative measures on a subject matter and acknowledges that the appropriate or the sole technique for assigning meaning to prepositions concerning a phenomenon is by obtaining data which can be quantified. The main characteristics of positivistic philosophy are; getting quantitative data grounded on theory and hypothesis testing. Data was therefore, prepared for analysis by numbering questionnaires, coding questions, and entering data into SPSS. The data was then exposed to factor analysis to demonstrate fitness for parametric analysis. Kaiser-Meyer-Olkin was used to ascertain sample adequacy and Bartlett's Test of sphericity was used to find out whether data had linear characteristics. Principal Component Analysis and Varimax approaches were used to extract factors with Eigen values equal to or greater than one (1) as recommended by Hair et al, (2016). Correlation analysis was done to evaluate level of relationship between variables. This study focused on cause and effect relationship, and therefore assessed the extent to which employees' team building programs influenced performance of MTNOs in Kenya. The researcher did regression analysis and hypotheses testing at $95 \%$ confidence level ( $5 \%$ level of significance).Simple regression analyses were used to obtain Beta coefficients and P-values which were used for hypotheses testing Hypothesis testing criteria was to reject Hypothesis $\mathrm{H}_{0}$ if $\mathrm{P}<.05$ and $\beta \neq 0$ or else accept $\mathrm{H}_{0}$. Employees team building programs and their influence on performance was analyzed through regression analysis, where R, R2 and adjusted R2 statistics were generated to reveal the connections between the regressor and the regressed variables. The association of variables regarding employees' team building programs as explained by employees' team building workshops, team building seminars, and team bonding meetings was defined by the regression model:

$\mathrm{OP}=1.237+.665 \mathrm{TBP}+\varepsilon$

Where:

OP is Performance of MTNOs,

1.237 is the $y$-intercept

$.665=$ the slope coefficient

$\mathrm{TBP}=$ Employees` team building programs

$\varepsilon=$ the error term

\section{Data Analysis, Findings and Interpretations}

\subsection{Factor Analysis}

Exploratory factor analysis was used to authenticate the questionnaire by testing convergence, legitimacy, and building construct validity. The measures of team building programs were subjected to factor analysis to establish their suitability for correlation and regression analysis. KMO and Bartlett's tests results for employees` team building programs are offered in table. 
Table 3: KMO and Bartlett's Test for Employees`Team Building Programs

Kaiser-Meyer-Olkin Measure of Sampling Adequacy

Bartlett's Test of Sphericity

$\begin{array}{cc}\text { Approx. Chi- Square } & 2331.449 \\ \text { df. } & 14 \\ \text { Sign } & .000\end{array}$

\section{Source: Research Data, 2020}

KMO and Bartlett's examinations output (table 3), indicated that the measures of employees' team building programs had KMO of .833 which was greater than the conventional minimum probability value of .5. A KMO of .833 meant that the sampling was adequate and this suggested that data was good and factor examination was suitable. Equally presented in table 3 was the result of Bartlett's test which was done on data to regulate the appropriateness of using factor analysis. For factor examination to be said to be suitable, the Bartlett's test needs to have a $\mathrm{P}-$ value of $.000<.05$. Total variances of employees` team building programs outcomes are explained in table 4 below.

Table 4: Total Variance of Employees` Team Building Programs Items

\begin{tabular}{ccccccc}
\hline \multirow{2}{*}{ Component } & Total & $\begin{array}{c}\text { Initial Eigenvalues } \\
\text { \% of } \\
\text { Variance }\end{array}$ & Cumulative \% & \multicolumn{2}{c}{$\begin{array}{c}\text { Extraction Sum of Squared Loadings } \\
\text { Total }\end{array}$} & $\begin{array}{c}\text { \%o of } \\
\text { Cumulative \% }\end{array}$ \\
\hline 1 & 6.359 & 27.553 & 27.553 & 6.359 & 27.553 & 27.553 \\
2 & 5.030 & 21.794 & 49.348 & 5.030 & 21.794 & 49.348 \\
3 & 1.795 & 7.777 & 57.124 & 1.795 & 7.777 & 57.124 \\
4 & 1.670 & 7.236 & 64.360 & 1.670 & 7.236 & 64.360 \\
5 & 1.591 & 6.891 & 71.251 & & & \\
6 & 1.491 & 6.460 & 77.711 & & & \\
7 & 1.454 & 6.299 & 84.010 & & \\
8 & 1.165 & 5.048 & 89.058 & & \\
9 & 1.003 & 4.346 & 93.404 & & \\
10 & .500 & 2.165 & 95.569 & & \\
11 & .332 & 1.440 & 97.008 & & \\
12 & .183 & .794 & 97.802 & & \\
13 & .179 & .777 & 98.579 & & \\
14 & .166 & .720 & 99.300 & & \\
15 & .162 & .700 & 100.000 & & \\
\hline
\end{tabular}

Extraction Method: Principal Component Analysis.

Source: Primary Data, 2020

The study found four factors attributable to employees 'team building programs which accounted for $64.360 \%$ of total variation in employees` team building programs constructs (table 4). Factor one accounted for $27.553 \%$ of the total variance, factor two accounted for $21.794 \%$ of the total variance, factor three accounted for $7.777 \%$ of the total variance and factor four accounted for $7.2367 \%$ of the total variance caused by employees ' team building programs items. The rotation component matrix results for employees` team building programs indicators showing convergent and divergent validity are shown in table 5 . 
Table 5: Rotated Matrix for Employees` Team Building Programs Items

\begin{tabular}{|c|c|c|c|c|}
\hline \multirow[b]{2}{*}{ Questionnaire Statement } & \multicolumn{4}{|c|}{ Components } \\
\hline & 1 & 2 & 3 & 4 \\
\hline $\begin{array}{l}\text { Team building workshops makes team members more personally invested into } \\
\text { the company leading to sense of ownership which boosts productivity }\end{array}$ & .013 & .903 & .007 & .047 \\
\hline $\begin{array}{l}\text { Team building workshops have caused high levels of employee commitment } \\
\text { leading to ownership of job activities hence higher efficiencies }\end{array}$ & .032 & -.035 & -.165 & .814 \\
\hline $\begin{array}{l}\text { Team building workshops makes employees to be more engaged with their team } \\
\text { roles improving effectiveness }\end{array}$ & .006 & .933 & .002 & .044 \\
\hline $\begin{array}{l}\text { Team building workshops makes employees to build cohesive teams with a } \\
\text { shared vision leading to ownership of team decisions for better productivity }\end{array}$ & -.048 & -.018 & .002 & -.047 \\
\hline $\begin{array}{l}\text { Team building workshops allow team members to agree on targets and this } \\
\text { makes them to have ownership of such targets and outcomes for higher } \\
\text { performance }\end{array}$ & -.022 & .877 & .003 & .045 \\
\hline $\begin{array}{l}\text { Team building seminars help employees to be self- accountable and to own team } \\
\text { targets to improve results }\end{array}$ & .955 & -.043 & -.018 & .026 \\
\hline $\begin{array}{l}\text { Team building seminars have resulted to positive attitudes of employees toward } \\
\text { their jobs causing ownership of their jobs and hence higher productivity }\end{array}$ & .029 & .879 & .080 & .001 \\
\hline $\begin{array}{l}\text { Team building seminars gives participants a strong sense of direction causing } \\
\text { them to own set objectives and to gain commitment to achieve them for better } \\
\text { team results }\end{array}$ & .956 & -.008 & .021 & .020 \\
\hline $\begin{array}{l}\text { Team building seminars leads to stronger team bonds which increases } \\
\text { ownership of team roles for improved team performance }\end{array}$ & .044 & .008 & .141 & .078 \\
\hline $\begin{array}{l}\text { Team building seminars help employees to gain competence and then ownership } \\
\text { of team projects for better results }\end{array}$ & .962 & .025 & .011 & .031 \\
\hline $\begin{array}{l}\text { Team bonding meetings makes members to be engaged enough to own their } \\
\text { job activities and this allows real-time problem-solving for increased team } \\
\text { performance }\end{array}$ & -.043 & .521 & -.056 & -.180 \\
\hline $\begin{array}{l}\text { Team bonding meetings increases interdependence and trust between team } \\
\text { members resulting to synergy and ownership which improves team productivity }\end{array}$ & .960 & .017 & -.004 & -.016 \\
\hline $\begin{array}{l}\text { Team bonding meetings boosts a deep sense of purpose and commitment to the } \\
\text { team mission increasing ownership of mission objectives for better performance }\end{array}$ & .048 & .051 & .554 & .369 \\
\hline $\begin{array}{l}\text { Brainstorming during team bonding meetings leads to ownership of set team } \\
\text { goals and eventually improving timeliness and achievement of such goals }\end{array}$ & -.017 & .014 & .866 & -.129 \\
\hline Team bonding meetings allow team members to define their te & .003 & .026 & .063 & .490 \\
\hline
\end{tabular}
accomplishment of corporate goals to have improved team performance

\section{Extraction Method: Principal Component Analysis. \\ Rotation Method: Varimax with Kaiser Normalization \\ Source: Primary Data, 2020}

Table 5, showed rotated component matrix had influence on the team building programs items and from research outcomes, the analysis had recognized four factors to be subjected into analysis. As indicated in the rotated matrix results (table 5), factor number one was highly correlated with; team bonding meetings increases interdependence and trust between team members resulting to synergy and ownership which improves team productivity (.960); team building seminars help employees to gain competence and then ownership of team projects for better results (.962); team building seminars gives participants a strong sense of direction causing them to own set objectives and to gain commitment to achieve them for better team results (.956) and; team building seminars help employees to be self- accountable and to own team targets to improve results (.955). Factor 2 was highly correlated with; team building seminars have resulted to positive attitudes of employees toward their jobs causing ownership of their jobs and hence higher productivity (.879); team building workshops allow team members to agree on targets and this makes them to have ownership of such targets and outcomes for higher performance $(.877)$; team building workshops makes employees to be more engaged with their team roles 
improving effectiveness (.933) Factor 3 was highly loaded with; brainstorming during team bonding meetings leads to ownership of set team goals and eventually improving timeliness and achievement of such goals (.866) and factor four was loaded with team building workshops have caused high levels of employee commitment leading to ownership of job activities hence higher efficiencies (.814).

\subsection{Correlation Analyses}

Correlation analysis amongst team building programs measures (team building workshops, team building seminars and team bonding meetings) and performance were done and results recorded in table 6.

Table 6: Employees`Team Building Programs and Organizations' Performance

\begin{tabular}{|c|c|c|c|c|}
\hline & $\begin{array}{c}\text { Organizations } \\
\text { performance }\end{array}$ & $\begin{array}{c}\text { Team building } \\
\text { workshops }\end{array}$ & $\begin{array}{c}\text { Team building } \\
\text { seminars }\end{array}$ & $\begin{array}{l}\text { Team bonding } \\
\text { meetings }\end{array}$ \\
\hline Organizations performance & 1 & & & \\
\hline Team building workshops & $.214^{*}$ & 1 & & \\
\hline Team building seminars & $.287^{*}$ & $.695^{*}$ & 1 & \\
\hline Team bonding meetings & $.147^{*}$ & $.359^{*}$ & $.492^{*}$ & 1 \\
\hline
\end{tabular}

*. Correlation is significant at 0.05 level (2-tailed).

Source: Research Data, 2020

As given in table 6, correlations between all the measures of employees' team building programs and organizations' performance of MTNOs were positive. The highest association was between; team building seminars and team building workshops $(\mathrm{r}=.695, \mathrm{P}<.05)$ followed by team bonding meetings versus team building seminars $(\mathrm{r}=.492, \mathrm{P}<.05)$. All the constructs of employees` team building programs correlated positively with organizations ' performance with team building workshops, team building seminars and team bonding meetings ( $\mathrm{r}$ $=.214, \mathrm{P}<.05),(\mathrm{r}=.277, \mathrm{P}<.05)$ and $(\mathrm{r}=.147, \mathrm{P}<.05)$ respectively. This implied that the dimensions of employees' team building programs (team building workshops, team building seminars and team bonding meetings) all had significant role in the relationship with performance of MTNOs in Kenya. The results agree with Hultin et al, (2017) who did a research to establish how employees' team building programs correlated with team performance. Hultin et al, (2017) concluded that employees` team building programs helps build high quality teams which influence firm`s performance positively.

\subsection{Regression Analysis}

The study's objective was to determine contribution of employees' team building programs on performance of MTNOs in Kenya. For this purpose the following null hypothesis was stated; $H_{0}$ : Employees team building programs have no relationship with performance of MTNOs in Kenya. The aggregate mean score of organizations' performance measures (dependent variable) of MTNOs; were regressed on the aggregate mean score of employees 'team building programs and the relevant research findings presented in table 7 below. Gaston, (2014) is of the proposition that standardized beta coefficients are used in deliberating study results and in model estimation in order to allow for comparison of relative influences of various model variables in the multiple regressions since they are independent of the original units of measurement. The value of $\mathrm{R}^{2}$ was obtained to show the level of variation in organizations' performance which was being explained by each of the employees` team building programs variables.

Table 7: Employees`Team Building Programs against Performance:

Goodness of Fit Model

\begin{tabular}{lcccc}
\hline Model & R & R Squared & Adjusted R Squared & Standard Error of the Estimate \\
1 & $.617^{\mathrm{a}}$ & .381 & .378 & .88113 \\
\hline
\end{tabular}

a. Predictors: (Constant), Employees` team Building Programs

Source: Primary Data, 2020

Model summary or goodness of fit model (table 7) results demonstrated that team building programs had a positive relationship with performance of MTNOs $(\mathrm{R}=.617)$. Team building programs had explanatory power over organizations' performance of MTNOs because it accounted for 38.1 percent of performance of MTNOs change $(\mathrm{R}$ square $=.381)$. The adjusted $\mathrm{R}^{2}$ of .378 means that the explanatory variables in this regression model accounted for $37.8 \%$ of variation in the performance of MTNOs and $62.2 \%(100-37.8 \%)$ of the variation is explained by other factors not included in the model. The adjustment of $\mathrm{R}^{2}$ by $3 \%$ is an indication that if the model was derived from the population rather than the sample, then it would account for approximately $3 \%$ less variance in the result. This shows that the contribution of team building programs to performance of MTNOs was statistically significant and this concurs with Hultin et al, (2017) who did a research to establish how team building programs correlated with team performance: Data analysis showed a correlation coefficient of $\mathrm{R}=0.521$ indicating an effective correlation between team building and team performance. Two-tailed significance was at $\mathrm{P}=0.000$, showing a high trustworthiness of results, meaning a great constructive association existed between team building 
programs and team performance. Hultin et al, (2017) concluded that team building programs helps build high quality teams which are able to influence firm`s performance positively. The ANOVA results of team building programs were given in table 8 .

Table 8: Employees` Team Building Programs against Performance

\begin{tabular}{|c|c|c|c|c|c|c|}
\hline \multicolumn{7}{|c|}{ ANOVA } \\
\hline Model & & $\begin{array}{l}\text { Sum of } \\
\text { Squares }\end{array}$ & Df & $\begin{array}{c}\text { Mean } \\
\text { Square }\end{array}$ & $\mathbf{F}$ & Sig. \\
\hline \multirow[t]{3}{*}{1} & Regression & 122.147 & 1 & 122.147 & 157.406 & $.000^{\mathrm{a}}$ \\
\hline & Residual & 198.756 & 256 & .776 & & \\
\hline & Total & 320.903 & 257 & & & \\
\hline
\end{tabular}

a. Predictors: (Constant), Employees` Team Building Programs

$b$. Dependent Variable: Organizations' performance

Source: Primary Data, 2020

$\mathrm{F}$ statistic specified that the ANOVA model was of importance at $(\mathrm{F}=157.406,(1,256) \mathrm{P}<.05)$. This means that this model can appreciably estimate variance in performance of MTNOs. ANOVA results (table 8) also showed that the overall contribution of employees' team building programs on performance of MTNOs was remarkable in that $\mathrm{P}<.05(\mathrm{P}=.000)$. Hypothesis $\left(\mathrm{H}_{0}\right)$ was tested using Beta coefficient and $\mathrm{P}$-value where the test criterion was to reject the null hypothesis if Beta coefficient was equal to zero and $\mathrm{P}>.05$, and results were presented in table 9.

Table 9: Employees` Team Building Programs against Performance

\section{Coefficients}

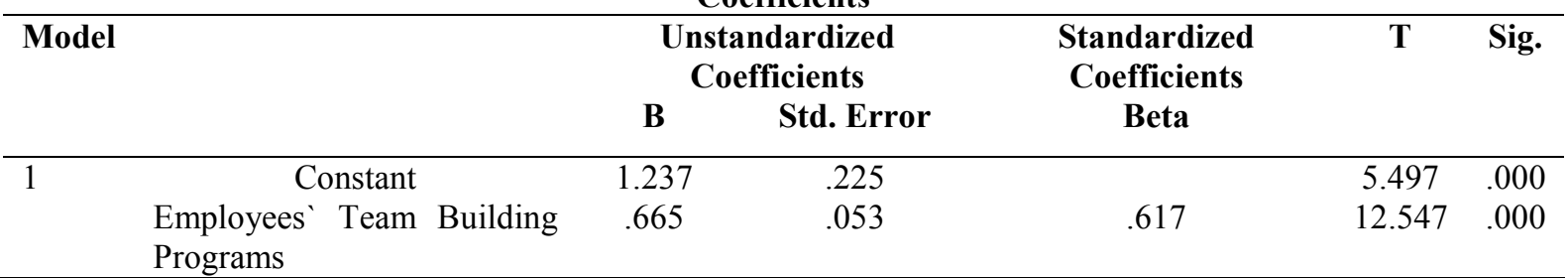

a Dependent Variable: Organizations' performance

Source: Primary Data, 2020

Model factor in table 9 exhibited that employees 'team building programs is an important contributor to the coefficient model of organizations' performance $(\mathrm{T}=5.497, \mathrm{P}<.05)$. The study`s coefficients outputs (table 9$)$ disclosed a numerically notable contribution of employees' team building programs to performance of MTNOs ( $\beta$ $=.617, \mathrm{P}=.000)$. The effect was established to be important considering $\mathrm{P}<.05$. The criterion for hypothesis testing was to reject the null hypothesis if $\beta \neq 0$ and $\mathrm{P}<.05$ or otherwise accept $\mathrm{H}_{0}$. In reference to the research outcomes, $\beta \neq 0$ and $\mathrm{P}<.05$, hence the researcher rejected $\mathrm{H}_{0}$ and posited that employees` team building programs contributes positively to performance of MTNOs. Emanating from output in table 9 is a simple regression equation utilizable in predicting the extent of performance of MTNOs taking one standard deviation increase in employees` team building programs:

$\mathrm{OP}=1.237+.665 \mathrm{TBP}+\varepsilon$

Where:

OP is Performance of MTNOs,

1.237 is the y-intercept

$.665=$ the slope coefficient

$\mathrm{TBP}=$ Employees` team building programs

$\varepsilon=$ the error term

Unstandardized Beta coefficient .617 stands for the likely upgrade in performance of MTNOs if standard deviation of employees` team building programs is improved by one unit. This means that, holding other factors constant, 1 standard deviance improvement in employees` team building programs would bring up performance by about .617 of a standard deviation. The study also conducted a multiple linear regression analysis on the employees 'team building programs measures which included team building workshops, team building seminars and team bonding meetings on performance of MTNOs. This was geared towards determining the employees` team building programs measure with the strongest influence on performance of MTNOs. The scores of organizations' performance of MTNOs (profit margins and market share) were regressed on the scores of the three employees ' team building programs measures (team building workshops, team building seminars and team bonding meetings) and results given in table 10 . 
Table 10: Employees` Team Building Programs Measures and Performance

Goodness of fit

\begin{tabular}{lccc}
\hline $\mathrm{R}$ & R Squared & Adjusted R Square & Std. Error of the Estimate \\
$.684^{\mathrm{a}}$ & .467 & .461 & 1.02386 \\
\hline
\end{tabular}

a. Predictors: (Constant), employees` team building programs measures (team building workshops, team building seminars and team bonding meetings)

Source: Primary Data, 2020

Regression outputs showed that performance of MTNOs correlates highly with employees` team building programs measures with $\mathrm{R}=.684$. The model showed $46.7 \%$ of the performance as being explained by employees ` team building programs measures $(\mathrm{R}$ squared $=.467)$. The adjusted $\mathrm{R}^{2}$ of .461 means that the explanatory variables in this regression model was responsible for $46.1 \%$ of difference in performance of MTNOs and $53.9 \%$ of the variation is due to other determinants not included in the model. The adjustment of $\mathrm{R}^{2}$ by $.6 \%$ is an indication that if the researcher used a census study rather than sampling, then the model would give approximately .6\% less variance in the result. The study result also concurred with the results of a study done by Sanyal \& Hisam, (2018) who studied teamwork and its influence on employee performance at Dhofar University and results showed coefficient ( $r$ ) was 0.819 . The ANOVA results of employees' team building programs measures against performance are exposed in table 11.

Table 11: Employees` Team Building Programs Measures and Performance

ANOVA

\begin{tabular}{cccccc}
\hline & Sum of Squares & df & Mean Square & F & Sig. \\
\hline Regression & 233.613 & 3 & 77.871 & 74.304 & $.000^{\text {a }}$ \\
Residual & 266.266 & 254 & 1.048 & & \\
Total & 499.880 & 257 & & & \\
\hline
\end{tabular}

a. Predictors: (Constant), employees` team building programs measures

b. Dependent Variable: Organizations' performance

Source: Primary Data, 2020

As reported in table 11, ANOVA outcomes reveal that employees team building programs measures overall influence on performance of MTNOs in Kenya was statistically significant since F = $74.304(3,254), \mathrm{P}<.05$. This means that this model could foretell the variance in performance of MTNOs. It agrees with a relevant study by Manzoor et al., (2011) who studied teamwork to establish how it affected performance of employees in Peshawar Province of Pakistan where after analysis of data on teamwork F-value of 120.140 was obtained and the regression coefficient was $\mathrm{R}=.843$ or $84.3 \%$. Regression coefficients for employees` team building programs measures and performance of MRNOs are expressed in table 12.

Table 12: Employees`Team Building Programs Measures and Performance

Coefficients

\begin{tabular}{lccccc}
\hline & \multicolumn{2}{c}{ Unstandardized Coefficients } & \multicolumn{3}{c}{$\begin{array}{c}\text { Standardized } \\
\text { Coefficients }\end{array}$} \\
Model & B & Std. Error & Beta & T & P \\
\hline (Constant) & .404 & .189 & & 2.138 & .034 \\
Team Building Workshops & .310 & .074 & .284 & 4.189 & .000 \\
Team Building Seminars & .340 & .068 & .324 & 5.000 & .000 \\
Team Bonding Meetings & .169 & .066 & .166 & 2.561 & .017 \\
\hline
\end{tabular}

a. Predictors: (Constant), employees` team building programs measures

b. Dependent Variable: Organizations' Performance

Source: Primary Data, 2020

Model factor in table 12 stipulated that all employees` team building programs measures had important contribution to the coefficients model of organizations' performance $(\mathrm{T}=2.138, \mathrm{P}<.05)$. The model parameters in table 12 had the indication that when team building seminars are used as a predictor, its contribution to the model is significantly higher than the other measures $(\mathrm{T}=5.000, \mathrm{P}<.05)$. Additionally, the predictive strength of team building workshops contribution in the coefficient model was similarly significant $(\mathrm{T}=4.189, \mathrm{P}<.05$. On the other hand, when team bonding meetings are used as a predictor, the contribution to the model is significantly important $(\mathrm{T}=2.561, \mathrm{P}<.05)$. The coefficients results show that all the measures of employees' team building programs had positive and significant influence on performance of MTNOs as follows; team building workshops had positively and significantly influenced performance of MTNOs $(\beta=.284, \mathrm{P}=.000)$, team building seminars also positively affected performance of MTNOs $(\beta=.324, \mathrm{P}=.000)$, team bonding meetings also had a positive effect on performance of MTNOs $(\beta=.166, \mathrm{P}=.017)$.

Given by results in table 12, is a single regression equation which is useful in predicting the proportion of performance in MTNOs for one standard deviation upgrade in team building workshops, team building seminars 
and team bonding meetings:

$\mathrm{OP}=.404+.310 \mathrm{TBW}+.340 \mathrm{TBS}+.169 \mathrm{TBM}+\varepsilon$

Where:

$\mathrm{OP}=$ Performance of MTNOs,

$404=$ the $Y-$ intercept constant $(\alpha=.404)$

$.310, .340, .169=$ an estimate of the expected increase in performance of MTNOs corresponding to an increase in use of team building workshops, team building seminars and team bonding meetings respectively. It means an increase in team building workshops by 1 unit standard deviation will boost performance on MTNOs by $31 \%$, rising team building seminars by I unit will improve performance by $34 \%$ and improving team bonding meetings by a single standard deviation will bring performance of MTNOs by $16.9 \%$

TBW $=$ Team Building Workshops,

TBS $=$ Team Building Seminars and

$\mathrm{TBM}=$ Team Building Seminars

$\varepsilon=$ Error term

\subsection{Discussion on Study Results}

The purpose of this study was to determine contribution of employees` team building programs on performance of MTNOs in Kenya. The study found that all the three constructs of team building programs had positive and significant contribution to performance of MTNOs in Kenya. As given in table 6, the correlations between all the measures of employees ' team building programs and performance of MTNOs were positive and significant. The highest association was between; team building seminars and team building workshops $(\mathrm{r}=.695, \mathrm{P}<.05)$ followed by team bonding meetings versus team building seminars $(\mathrm{r}=.492, \mathrm{P}<.05)$. All the constructs of employees` team building programs correlated positively with organizations' performance with team building workshops, team building seminars and team bonding meetings $(\mathrm{r}=.214, \mathrm{P}<.05),(\mathrm{r}=.287, \mathrm{P}<.01)$ and $(\mathrm{r}=.147, \mathrm{P}<.05)$ respectively.

Regression outputs showed that performance of MTNOs correlates highly with employees' team building programs measures with $\mathrm{R}=.684$ (table 10 ). The model showed $46.7 \%$ of the organizations' performance as being explained by employees` team building programs measures ( $\mathrm{R}$ squared $=.467$ ). The adjusted $\mathrm{R}^{2}$ of .461 means that the explanatory variables in this regression model was responsible for $46.1 \%$ of difference in performance of MTNOs and $53.9 \%$ of the variation is due to other determinants not included in the model. The adjustment of $\mathrm{R}^{2}$ by .6\% is an indication that if the researcher used a census study rather than sampling, then the model would give approximately .6\% less variance in the result.

\section{Conclusion}

The study concluded that there was a statistically significant positive contribution of employees ' team building programs on organization's performance (P-value $<.05)$. The study results also concluded that contribution of employees' team building programs constructs (team building workshops, team building seminars and team bonding meetings) on organizations ' performance was statistically significant in that the P-values were $<.05$. The study therefore concluded that team building programs contributes positively to performance of MTNOs in Kenya.

\subsection{Recommendation}

The study recommended that organizations should develop cohesive teams through employees` team building programs to improve performance. The study also recommends a similar study to be carried out using a longitudinal research design.

\section{References}

Al Salman, W., \& Hassan, Z. (2017). Impact of Effective Teamwork on Employee Performance. International Journal of Accounting \& Business Management, 4(1), 76-85.

Armstrong, M. (2012). Armstrong's Handbook of Human Resource Management Practice. London: Kogan Page. Ashforth, B. E., (1989). Social identity theory and the organization. The Academy of Management Review, 14, 2039.

Banerjee, P. (2014). A Study of Effective Team Building in Relation to Organizational Culture and Organizational Climate in Universities in Delhi. sage journals, 1(2), 211-225.

Ciasullo, V. M., Cosimato, S., Gaeta, M., \& Palumbo, R. (2017). Comparing two approaches to team building: a performance measurement evaluation", Team Performance Management:. An International Journal, 33(8), $333-351$

Doan, T. T. (2015). A Showcase of Teamwork Enhancement through Teambuilding Activities in Vietnam. Journal of Business Administration Research, 4(2), 40-45.

Edson, M. C., Henning, P. B., \& Sankaran, S. (2016). A Guide to Systems Research: Philosophy, Processes and 
Practice. New York: Springer.

Gaston, L. (2014). Hypothesis Testing Made Simple. Create Space Independent Publishing Platform.

Gino, F. (2015, December 7). How to Make Employees Feel Like They Own Their Work. Harvard Business Review.

Guchait, P., Lei, P., \& Tews, M. J. (2016). Making Teamwork Work: Team Knowledge for Team Effectiveness. The Journal of Psychology, 150(3), 300-317.

Hair, J. F., Black, B., Babin, B., \& Anderson, R. E. (2016). Multivariate Data Analysis (7th ed.). Upper Saddle River, NJ: Pearson Education.

Hultin, Y. X., Zhang, C., \& Hu, Y. (2017, may 30). Does team building support the creation of high-performing teams? A perceptual study of the effectiveness of team building. Retrieved July 18, 2018, from Lund University Repository: lup.lub.lu.se/student-papers/record/8926400/file/8926402.pdf

Kaplan, M., Dollar, B., Melian, V., Van Durme, Y., \& Wong, J. (2016). Human capital trends 2016 survey. Oakland, CA: Deloitte University Press. Retrieved from deloitte.com/us/en/pages/ humancapital/articles/introduction-human-capital-trends.html

Krejcie, R. V., \& Morgan, D. W. (1970). Determining Sample Size for Research Activities. Educational and Psychological Measurement, 30, 607-610.

Mael, F. A., \& Ashforth, B. E. (2001). Identification in work, war, sports, and religion: Contrasting the benefits and risks. Journal for the Theory of Social Behaviour, 31, 197-222.

Manzoor, S. R., Ullah, H., Hussain, M., \& Ahmad, Z. M. (2011). Effect of Teamwork on Employee Performance. International Journal of Learning and Development, 1(1), 110-126.

Wilson, J. (2010). "Essentials of Business Research: A Guide to Doing Your Research Project”. New York: SAGE Publications.

Sanyal, S., \& Hisam, M. W. (2018). The Impact of Teamwork on Work Performance of Employees: A Study of Faculty Members in Dhofar University. Journal of Business and Management, 20(3), 15-22.

Sekaran, U., \& Bougie, R. (2016). Research Methods For Business: A Skill Building Approach. New York : John Wiley \& Sons.

Sukhatme, P. V., Sukhatme, B. V., Sukhatme, S., \& Asok, C. (1984). Sampling Theory of Surveys with Applications. Ames, Iowa: Iowa State University Press.

Tajfel, M. (1978). Differentiation between social groups. London: Academic Press.

Trepte, S., \& Loy, L. S. (2017). Social Identity Theory and Self - Categorization Theory. New Jersey: John Wiley \& Sons, Inc.

Udu, G. O., \& Aturu-Aghedo, C. A. (2016). Effects of Participative Decision Making on the Performance of Federal Airports Authority of Nigeria (Faan), Lagos. International Journal of Human Resource Management and Research (IJHRMR), 6(4), 2249-6874. 